\title{
COMPETITIVE CAPABILITIES OF SMALL AND MEDIUM-SIZED ACCOMMODATIONS (SMSAs) IN EAST COAST OF MALAYSIA
}

\author{
NUR FARAH ZAFIRA ZAIDI, SITI NUR ‘ATIKAH ZULKIFFLI” AND NOOR ZATUL IFFAH \\ HUSSIN
}

School of Maritime Business and Management, Universiti Malaysia Terengganu, 21030 Kuala Nerus, Terengganu Darul Iman, Malaysia

"Corresponding author: atikahzulkiffli@umt.edu.my

\begin{abstract}
The number of small and medium-sized accommodations (SMSAs) has increased in Malaysia in tandem with the growth of the tourism industry worldwide. The states involved in this study were Terengganu, Kelantan and Pahang. The SMSAs in these states are rated using Orchid rating, namely 1-Orchid, 2-Orchid and 3-Orchid, generated by the Ministry of Tourism, Arts and Culture Malaysia (MOTAC). This study applied the Resource-based View (RBV) theory to investigate four factors (marketing management, human resources management, innovation capability management and information technology) assumed to be competitive capabilities that may influence accommodation's performance. The objective of the study is to examine whether the four factors influence the performance of Orchid-rated accommodations located in the East Coast of West Malaysia. The results revealed that the four factors do not have any relationship with the accommodation's performance. The analysis also singled out one argument of the director of SMSA that competitive capabilities are not important to their business. This argument coincides with the results of the analysis that the four factors are not significant with regards to the accommodations' performance.
\end{abstract}

Keywords: Tourism Industry, Competitive Capabilities, Orchid Rating Categories, East Coast of West Malaysia, Resource-Based View.

\section{Introduction}

The number of tourists to Malaysia increased from 25.72 million in 2015 to 26.76 million in 2016 due to the many historical and interesting places in the country. For the same reason, Tourism Malaysia has predicted another increase in 2017 to approximately 31.8 million (source: Tourism Malaysia, 2017). It can be seen that tourism industry can generate good income for the nation. Thus, accommodation providers need to focus on providing appropriate tourist facilities that can make tourists feel satisfied throughout their stay.

However, with the increase in the number of tourists, there are problems faced by the small and medium-sized accommodations (SMSAs). The increase in the number of tourists has created the opportunity for companies to start or expand their business in this area. The good news is there is an increase in the number of accommodations in Malaysia. The not-so-good news is the growing number of SMSAs has increased the number of competitors and subsequently intense competition will follow.

Moreover, according to Chan and Quah (2008), competition in terms of new entrants and intense competition are the main issues faced by ownermanagers in managing their accommodation business. The human resource component is another issue or problem faced by the SMSAs. For example, not being able to pay good salary to skilled workers and poor communication skills are some of the human resource problems (Chan \& Quah, 2008). Also, lack of training provided to the staff will cause a decline in accommodation' performance. Hence, the purpose of this study is to investigate whether the SMSAs in the East Coast of West Malaysia are capable of competing with each other or not. This is because healthy competition among the small and medium-sized accommodations will increase their performance.

This study concentrated on three states in the East Coast of West Malaysia - Terengganu, Kelantan and Pahang - as they are unique, bordering the South China Sea. The coasts and many interesting places have caused many tourists to visit the three states. Terengganu offers many cultural heritage of the Malays that have originated for thousands of years in Terengganu. Interestingly, the state is still preferred by the locals and foreign tourists (Halim et al., 2012). Kelantan, which is famous for its own rural lifestyle of Malay tradition, has a different culture than the other states. Pahang, which is the largest 
state in Malaysia, prompts many tourists come there for its many attractions, such as Genting Highland, Cameron Highland, and Fraser's Hill.

This study involved all the accommodations in Terengganu, Kelantan and Pahang which are in the Orchid rating category maintained by the Ministry of Tourism and Culture Malaysia (MOTAC). The main objective of this study is to examine whether four variables, namely (1) marketing management, (2) human resource management, (3) innovation capability management, and (4) information technology are capable of influencing the performance of the accommodations in the East Coast of West Malaysia. The data was analyzed using the Statistical Package for Social Sciences (SPSS) software. Findings from this study can help the SMSAs to know about their potential in terms of competitive capability in the industry. Apart from that, the SMSAs are also able to know about their current performance level and how to improve it. It appears that many accommodation providers are not confident in their ability to compete in the market place.

\section{Definition of Small and Medium-sized Accommodation}

From previous studies, there is no clear-cut description of the SMSA. Moreover, according to Morrison and Conway (2007), there is no universally accepted definition of the SMSA. Alternatively, the SMSA can be defined by relating it to the small and medium-sized enterprise (SME). SME is defined in accordance with two criteria-number of full-time employees and sales turnover of the firm (SME Corp, 2017).

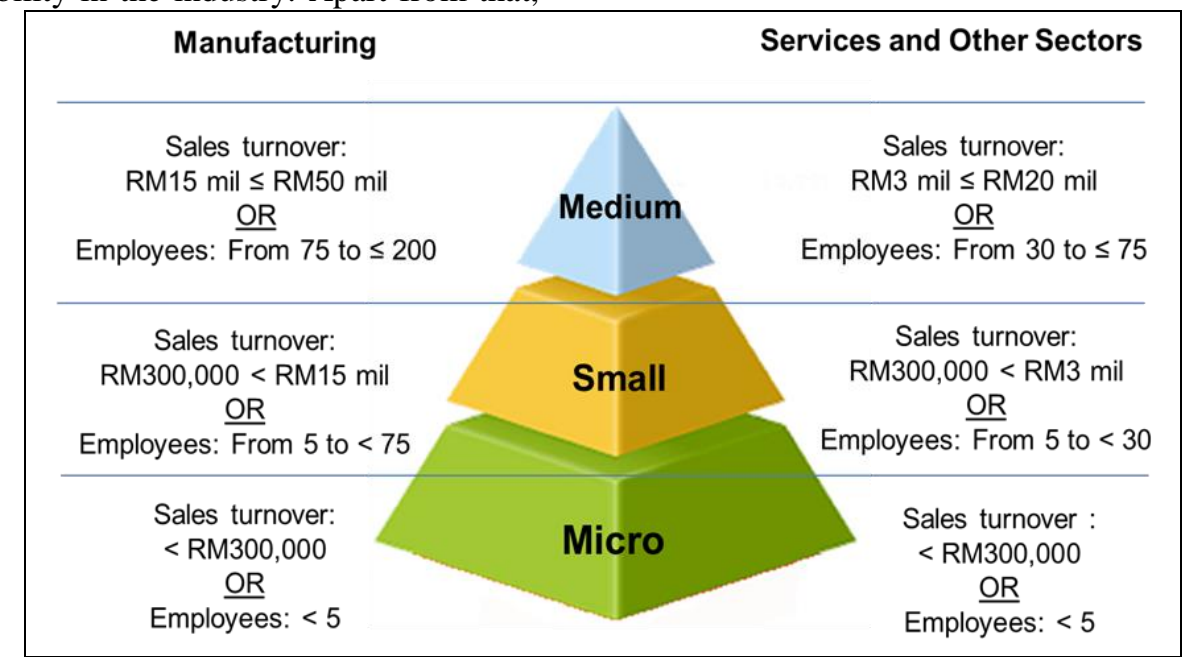

Figure 1: Definition of SMEs under Manufacturing, and Services and Other Sectors Source: SME Corp (2017)

Figure 1 shows that SMEs under the Services and Other Sectors are firms which have the total number of full-time employees not exceeding 75 and sales turnover not exceeding RM20 million (SME Corp, 2017). Therefore, the SMSAs can fall under the Services and Other Sectors, a category of SMEs which includes hotels and restaurants, businesses, trade distributions, financial intermediations, and others. According to previous studies, SMEs play a major role in Malaysia (Kayadibi et al., 2013). The Ministry of Tourism and Culture Malaysia (MOTAC) has come up with Orchid Classification, to complement the Hotel Classification Schemes, also known as Star Rating (MOTAC, 2017). Accommodations that do not qualify for any of the Star ratings (1-5) are rated under the Orchid rating. This is because the Orchid Classification Scheme was specifically formulated by MOTAC to rate the SMSAs. The Orchid rating awarded to SMSAs is based on several criteria such as safe, good and clean accommodation. In addition, an SMSA is classified as a 1-Orchid level, 2-Orchid level or 3-Orchid level based on specifications listed by MOTAC. Diverse accommodation types such as inns, bounding houses, rest houses, lodging houses, bed and breakfast, and hostels are classified under the Orchid Classification Scheme (MOTAC, 2017).

\section{Literature Review}

This section discusses the literature related to competitive capabilities and four factors that can be considered as independent variables - marketing management, human resources management, innovation capabilities management, and information technology.

\section{Resource-based View Theory}

According to Barney (1991), RBV theory posits that a firm is one that is in control of all its assets, capabilities, strong characteristics, information, knowledge, and etc. Being so, a firm is able to devise and implement strategies that can improve its efficiency and effectiveness. Thus, RBV theory focuses on the ability of a firm to establish competitive capabilities and competitive advantage (Gratzer, 2003). In addition, RBV 
theory also focuses on the structural analysis of a firm for competitive capability purposes, based on the popular competitive forces model (Porter, 1985).

\section{Competitive Capabilities}

According to Corbett and Wassenhove (1993), competitive capabilities come under the marketing mix of a firm, which comprise product, price, place and promotion. In the context of SMSAs, products can also be referred to as services provided by the SMSAs. The unique characteristics of services include inseparability, intangibility, perishability and heterogeneity. In addition, it is important for the SMSAs to retain staff who have provided excellent services to customers to maintain customer satisfaction.

Competitive capabilities are external in terms of managing competition with competitors. Competitiveness is important for a business as it can increase the performance level of a firm or accommodation provider. For this study, it is important to understand the strength of the four factors as they relate to competitive capabilities. According to Saxenian (1994), a firm needs to maintain its competitive capabilities in order to be successful in terms of sustainability. Besides that, the strategy that is implemented with regards to competitive capabilities is actually an organization's initiative for growth of the firm (Porter, 1996).

\section{Marketing Management}

Marketing is a strategy that can help a firm achieve competitive capabilities. According to Kotler and Keller (2011), marketing is about creating, exploring, and delivering value to satisfy the needs and wants of the target market, which comprises customers and consumers. In the context of SMSAs, it means the SMSAs need to deliver excellent services to customers as that can enhance their performance. In another perspective, Porter (1985) defines marketing as a reference for competitive strategies of a firm. Thus, marketing management requires competency as that is crucial for a firm's growth (Chaston et al., 2001). Besides that, marketing is also important to advance a business to a higher level. Therefore, a firm achieves higher performance when it assigns higher priority to marketing compared to the other business functions (Brooksbank et al., 1992).

Particularly for the SMSAs, they need to focus more on marketing as doing so can enhance their competitive capabilities. In addition, this also implies that the particular firm excels in its performance. Additionally, an effective marketing requires a specialized skill that can enable the SMSAs to influence their target customers with regards to the accommodation offerings, Therefore, effective marketing is about possessing effective communication skills and effective capability to define and target their markets. As with other businesses, the SMSAs should employ market expansion strategies and adopt a proactive approach in satisfying and appreciating customers. Thus, marketing management is indeed critical in improving the performance of accommodation providers, for them to remain competitive and sustainable in the local and global markets.

\section{Human Resources Management}

Human resources management is another factor that may help a firm to achieve competitive capabilities. According to Barney (1991), from the RBV perspective, human resources management is hypothesized to have a positive relationship with firm performance. Previous studies have also hypothesized likewise, whereby a positive relationship exists between human resources management and firm performance (Zheng et al., 2006). Rationally, human resources management will also have a positive relationship with accommodation performance.

Besides that, past studies have also hypothesized that there is a positive relationship between entrepreneurship training on human resources management and a firm's performance (Petridou et al., 2009). In other words, the SMSAs need to train their employees to become more productive and responsible in their jobs. Moreover, there appears to be a large number of empirical evidence and theories about the impact of human resources management on firms' performance. Logically, human resources management must have the capability to manage its human resources as only then can a firm gain its competitive advantage (Barney \& Wright, 1997). Overall, it is hypothesized that competitive advantage is generated by both competitive capability and improvement in accommodation performance.

\section{Innovation Capabilities Management}

Innovation capabilities management is also hypothesized to be a factor contributing to competitive capabilities of a firm. According to Asree et al. (2010), studies about innovation have been conducted for the hotel industry in Malaysia. It was concluded that incremental innovation could improve the existing services and boost the potential of establishing those services (Ettlie, 1983). In other words, incremental innovation can help develop better services for a firm. On another perspective, radical innovations are actually a major innovation for the existing services (Chandy \& Tellis, 2000). What it means here is that radical innovation is another capability that can transform the existing services.

In previous studies, researchers hypothesized that if a firm explores deeper into the innovation capabilities that it has, the firm can get more benefits (Saunila, 2014). 
Meanwhile, according to Rosli (2012), process innovation helps to cut down production costs resulting in a higher revenue for a firm. This implies an improvement in the accommodation's performance will follow. Moreover, according to Awuah and Amal (2011), innovation is a very important mechanism for establishing a firm's competitiveness in business. Thus, innovation can be considered a capability of a firm (Awuah \& Amal, 2011). Accordingly, the enhanced capability through innovation can lead to competitive capability and subsequently good profitability for a firm (Roberts \& Amit, 2003).

\section{Information Technology}

Another important resource of the accommodation business is information technology. This means that the SMSAs also need to focus on information technology. Information technology can also generate competitive capabilities for a business firm. Specifically, information technology can be regarded as a component of planning to increase a hotel's business performance (Law \& Jogaratnam, 2005). Additionally, according to Hong et al. (2006), a firm needs to apply efficient technology via using the internet and machineries for production.

Similarly, the e-commerce technology can also enhance a firm's business performance by integrating the important functions (Garces et al., 2004). By having all the above, the SMSAs can create an organizational structure that will be more efficient. Additionally, Phan (2003) suggested creating inter-organizational virtual structures with integration that can make a firm to become more efficient. Evidence from previous studies has proven that information technology is significant in improving business performance, and this should be able to stimulate the Malaysian economy. Many businesses have also used the technology to integrate their customers as this is also believed to generate competitive advantage for the businesses (Phan, 2003). This initiative is also considered a competitive capability that can enhance business performance. Therefore, information technology is another core competency that is crucial for a firm's growth (Chaston et al., 2001).

\section{Accommodation Providers' Performance}

The performance of a firm can be reported from the aspects of marketing and financial, for example, sales growth (Feng et al., 2008). This was also supported by Wood (2006), documented from a previous study. Researchers have assessed the performance of a firm based on financial ratios such as return on assets (ROA), return on investment (ROI) and turnover. In addition, business performance can also be measured based on growth of sales as a result of increase in profits (Buttner $\&$ Moore, 1997). Thus, the SMSAs need to generate income from their operations, i.e., services, by strengthening the independent variables, namely (1) marketing management, (2) human resources management, (3) innovation capabilities management, and (4) information technology.

According to Morrison and Teixeira (2004), bedroom-occupancy rate, guest satisfaction and breakeven point are alternative variables to measure the performance of the services sector, which is the category the SMSAs fall under based on the nature of the SMSAs. As has been mentioned earlier, competitive capabilities have the potential to influence business performance (Kim, 2006). It has also been understood earlier that to make the SMSAs successful and gain competitive capabilities, they need to strategize on their marketing, human resources, innovation capabilities and information technology.

There are two types of measures in evaluating performance, which are the subjective measures and the objective measures. According to Dawes (1999), the objective measures are benchmarked to the industry. The subjective measures include culture, time horizons, economic condition and industry types (Song et al., 2005). According to Wall et al. (2004), many researchers have asked directors to measure the performance of their business by using the subjective measures for the reason that data can be collected via questionnaire. Thus, this study used the subjective measures and the scope of study was the SMSAs located in the East Coast of Peninsular Malaysia. 
Theoretical Framework and Hypothesis Development

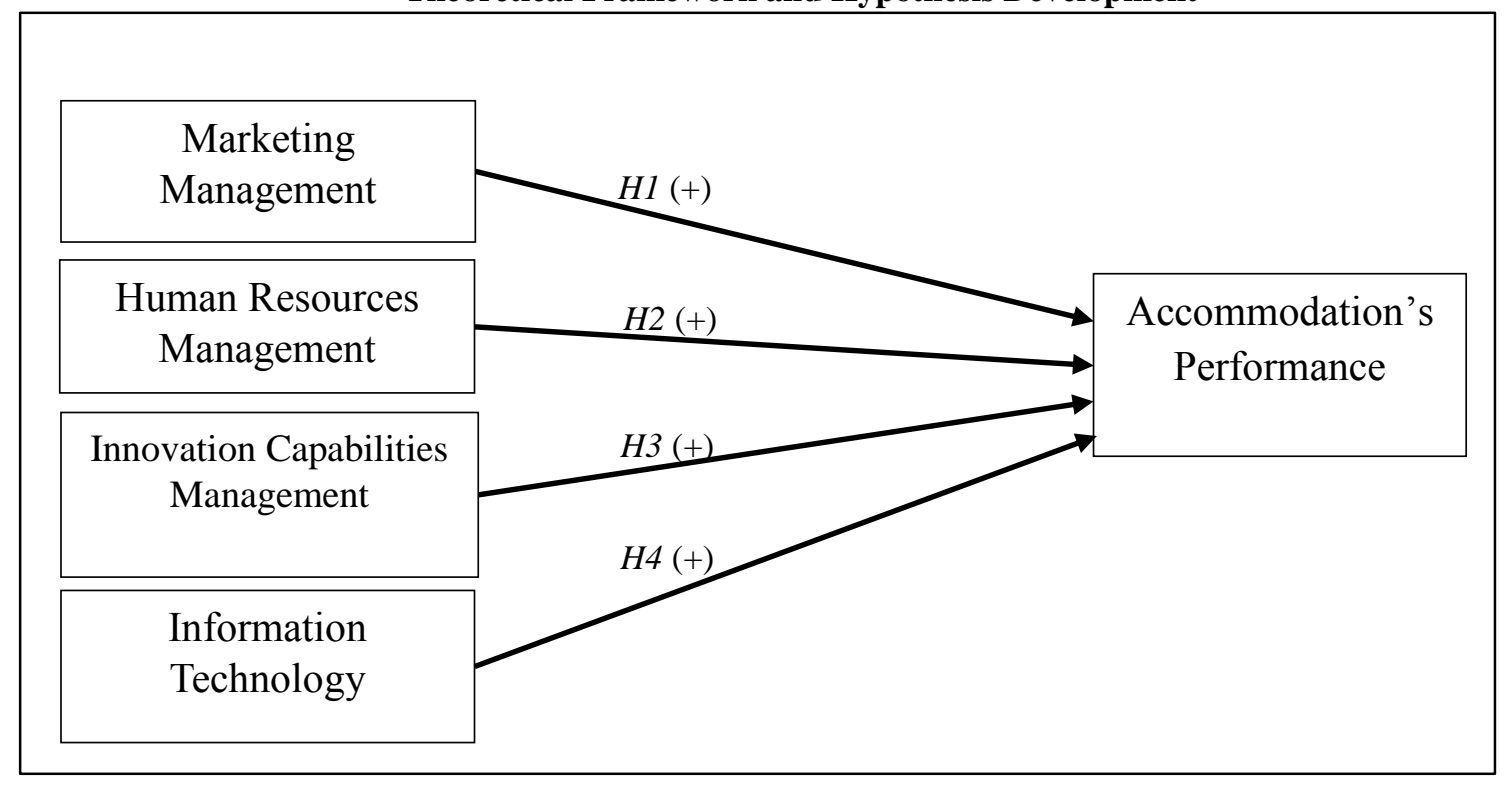

Figure 2: Theoretical Framework of the Study

Figure 2 illustrates the theoretical framework of the study from which four hypotheses are derived:

Hypothesis 1 (H1): There is a positive relationship between marketing management and Orchid-rated accommodation's performance.

Hypothesis 2 (H2): There is a positive relationship between human resources management and Orchid-rated accommodation's performance.

Hypothesis $3(\boldsymbol{H 3})$ : There is a positive relationship between innovation capabilities management and Orchid-rated accommodation's performance.

Hypothesis $4(\boldsymbol{H 4})$ : There is a positive relationship between information technology and Orchid-rated accommodation's performance.

\section{Methodology}

For the study, the population comprised SMSA providers located in the East Coast of West Malaysia including Terengganu, Kelantan and Pahang. According to MOTAC (2017), the population of SMSAs located in the East Coast of West Malaysia totaled 144. The population for this study was chosen based on the following criteria:

a. The SMSAs were registered under the Orchid Classification Scheme by MOTAC, different from the star rating of hotel accommodation providers.

b. The MOTAC provided a list of accommodation providers in all the states under the Star rating category and Orchid rating category.

Besides that, MOTAC updated the information daily and also provided other information about tourism in Malaysia. MOTAC also provided complete information about accommodation providers such as the accommodation's name, phone number, address, email address and the classification scheme of the accommodation. The probability sampling technique was chosen for this study. Under the probability sampling design, the simple random sampling technique is used to select a subject for every element in the population (Sekaran \& Bougie, 2009). Therefore, each of the 144 SMSAs had a known and equal chance of being selected as a subject. According to Raosoft (2004), the population size of 144 needs to have a sample size of 105. Thus, 105 was the minimum recommended sample size for this study. Questionnaire was administered to 105 SMSAs located in the East Coast of West Malaysia to obtain feedback on the subject's level of agreement with several statements, based on a five-point Likert measurement scale.

\section{Data Analysis Reliability Analysis}

The independent variables (marketing management, human resources management, innovation capabilities management, information technology) and the dependent variable (accommodation's performance) were assessed for their reliability using reliability analysis. According to the Sekaran (2009), Cronbach's Alpha values of 0.70 and 0.80 are considered to be acceptable. Cronbach's Alpha is a reliability coefficient that measures how items in a set are positive with each other. If the reliability value is less than 0.60 , it is considered to be poor, reliability value of 0.7 is acceptable, and reliability values of more than 0.8 is satisfactory (Sekaran, 2009).

As illustrated in Table 1, the Cronbach's Alpha value for marketing management is 0.723 , which is acceptable. Three questions under marketing management were deleted in order to get a higher Cronbach's Alpha value. For human resources 
management, the value of 0.687 is acceptable as it is close to 0.7. As mentioned earlier, according to Sekaran (2009), the Cronbach's Alpha value of 0.7 is acceptable. For human resources management, 4 questions were deleted. The innovation capabilities management's value is 0.750 Cronbach's Alpha after 2 questions were deleted to get a higher value. For information technology, the value of Cronbach's Alpha is 0.799, while for accommodation's performance, the value is 0.797 . Thus, all the variables' values are considered to be acceptable.

Table 1: Table of Reliability Analysis

\begin{tabular}{lcc}
\hline \multicolumn{1}{c}{ Variable } & Items & Cronbach's Alpha \\
\hline Marketing management & 7 & .723 \\
\hline Human resources management & 6 & .687 \\
\hline Innovation capabilities management & 8 & .750 \\
\hline Information technology & 10 & .799 \\
\hline Accommodation's performance & 9 & .797 \\
\hline
\end{tabular}

\section{Correlation}

Table 2 illustrates the correlation coefficients of the 4 independent variables in relation to the dependent variable using a 2-tailed test. This analysis checks for linear relationship and strength between the independent and dependent variables (Pallant, 2005). The value for marketing management, which is 0.011 , is considered to be significant with accommodation's performance. Next, the factor coefficient for human resources management, which is 0.038 , is also significant with accommodation's performance. These two variables are significant as the values are below 0.05. Meanwhile, the correlation of innovation capabilities management and information technology with accommodation's performance are not significant, with values of 0.452 and 0.865 respectively.

Table 2 Table of Correlation

\begin{tabular}{|c|c|c|c|c|c|c|}
\hline & & MM & HRM & ICM & IT & $\mathbf{A P}$ \\
\hline \multirow[t]{3}{*}{ MM } & Pearson Correlation & 1 & $.411^{* * *}$ & .172 & .008 & $.356^{*}$ \\
\hline & Sig. (2-tailed) & & .003 & .232 & .958 & .011 \\
\hline & $\mathrm{N}$ & 50 & 50 & 50 & 50 & 50 \\
\hline \multirow[t]{3}{*}{ HRM } & Pearson Correlation & $.411^{* *}$ & 1 & .133 & -.225 & $.294^{*}$ \\
\hline & Sig. (2-tailed) & .003 & & .357 & .117 & .038 \\
\hline & $\mathrm{N}$ & 50 & 50 & 50 & 50 & 50 \\
\hline \multirow[t]{3}{*}{ ICM } & Pearson Correlation & .172 & .133 & 1 & $.669^{* *}$ & .109 \\
\hline & Sig. (2-tailed) & .232 & .357 & & .000 & .452 \\
\hline & $\mathrm{N}$ & 50 & 50 & 50 & 50 & 50 \\
\hline \multirow[t]{3}{*}{ IT } & Pearson Correlation & .008 & -.225 & $.669^{* *}$ & 1 & .025 \\
\hline & Sig. (2-tailed) & .958 & .117 & .000 & & .865 \\
\hline & $\mathrm{N}$ & 50 & 50 & 50 & 50 & 50 \\
\hline \multirow[t]{3}{*}{$\mathbf{A P}$} & Pearson Correlation & $.356^{*}$ & $.294^{*}$ & .109 & .025 & 1 \\
\hline & Sig. (2-tailed) & .011 & .038 & .452 & .865 & \\
\hline & $\mathrm{N}$ & 50 & 50 & 50 & 50 & 50 \\
\hline
\end{tabular}

**. Correlation is significant at the 0.01 level (2-tailed).

*. Correlation is significant at the 0.05 level (2-tailed).

\section{Multiple Regression Analysis}

As illustrated in Table 3, the adjusted $r^{2}$ of this study is 0.083 . The value is very low. Based on the value of $r^{2}$, the explanatory variables are not significant in explaining for the variation in the dependent variable. The $r^{2}$ is about 0.158 and the standard error of this estimate is 0.431 . The multiple regression analysis is used to check whether the 4 independent variables are significant or non-significant. 
Table 3 Table of Multiple Regression Analysis

\begin{tabular}{|c|c|c|c|c|}
\hline \multicolumn{5}{|c|}{ Model Summary } \\
\hline Model & $\mathrm{R}$ & R Square & Adjusted R Square & Std. Error of the Estimate \\
\hline 1 & $.397^{\mathrm{a}}$ & .158 & .083 & .431 \\
\hline
\end{tabular}

a. Predictors: (Constant), IT, MM, HRM, ICM

Table 4 illustrates the relationship between the four independent variables and accommodation performance. All of the factors are not significant because the value is higher than 0.05. It is not significant due to the low value of $r^{2}$ of 0.083 .

Table 4 Table of Coefficient Regression Analysis

\begin{tabular}{|c|c|c|c|c|c|c|}
\hline \multicolumn{7}{|c|}{ Coefficients $^{\mathbf{a}}$} \\
\hline \multirow{2}{*}{\multicolumn{2}{|c|}{ Model }} & \multicolumn{2}{|c|}{$\begin{array}{l}\text { Unstandardized } \\
\text { Coefficients }\end{array}$} & \multirow{2}{*}{$\begin{array}{c}\begin{array}{c}\text { Standardized } \\
\text { Coefficients }\end{array} \\
\text { Beta } \\
\end{array}$} & \multirow[t]{2}{*}{$\mathrm{T}$} & \multirow[t]{2}{*}{ Sig. } \\
\hline & & $\mathrm{B}$ & Std. Error & & & \\
\hline \multirow[t]{5}{*}{1} & (Constant) & .641 & .865 & & .741 & .462 \\
\hline & MM & .303 & .166 & .276 & 1.823 & .075 \\
\hline & HRM & .240 & .195 & .202 & 1.226 & .226 \\
\hline & ICM & -.019 & .190 & -.020 & -.099 & .921 \\
\hline & IT & .065 & .163 & .081 & .398 & .692 \\
\hline
\end{tabular}

a. Dependent Variable: AP

\section{Conclusion and Recommendation}

This study discusses the importance of marketing management, human resources management, innovation capabilities management, and information technology to the SMSA providers. Based on the results of previous studies, the four factors (marketing management, human resources management, innovation capabilities management, information technology) have been hypothesized to have a relationship with accommodation's performance. The findings of this research are not similar to the ones in previous studies.

The results revealed that the four factors do not have any relationship with the performance of SMSAs located in the East Coast of West Malaysia. Many directors think that the 4 factors are not important for the SMSAs because their business is only classified under the Orchid category. Their understanding is that the Orchid category is for budget hotels while the Star category is for more expensive hotels. The reason they ventured into accommodation business was to obtain income to cover their own expenses and not to compete with their competitors in the hospitality industry. The findings would have been different if this study focussed on hotels under the Star category. Previous studies hypothesized that the 4 factors were significant in their relationship with accommodation's performance. Their subjects were the Star rated hotels, and most likely they were always concerned with their reputation in the hospitality industry.
The data for this study was collected from a sample of 50 respondents who are directors or managers attached to the respective SMSAs. From the analysis, the reliability values indicate that the 4 hypotheses are positive, but their coefficient regressions are not significant. Based on the results of the multiple regression analysis, the analysis does not support $H 1$ ( $>0.05)$. This means that the competitive capabilities are not relevant for the SMSAs located in the East Coast of West Malaysia. The generalizability of the study's results is limited due to the low response rate for the online survey. Those who did not answer the questionnaire might have different perception towards this research. It is suggested that future research seek to explore the functions of other competitive capabilities such as customer relationship with regards to accommodation's performance.

\section{References}

Asree, S., Zain, M., and Razalli, M. R. (2010). Influence of leadership competency and organizational culture on responsiveness and performance of firms. International Journal of Contemporary Hospitality Management, 22: 500-516.

Awuah, G. B. \& Amal, M. (2011). Impact of Globalization: The ability of less developed countries' (ldcs') firms to cope with opportunities and challenges. European Business Review, 23(1), 120-132. 
Barney, J. (1991). Firm resources and sustained competitive advantage. Journal of Management, 17(1), 99-120.

Barney, J. B. \& Wright, P. M. (1997). On becoming a strategic partner: the role of human resources in gaining competitive advantage. Human Resource Management, 37(1) 31-46.

Brooksbank, R., Kirby, D. A. \& Wright, G. (1992). Marketing and company performance: an examination of medium sized manufacturing firms in Britain. Small Business Economics, 4(3) 221-236.

Buttner, E. H. and Moore, D. P. (1997). Women's organizational exodus to entrepreneurship: self reported motivations and correlates with success. Journal of Small Business Management, 35 (1), 3446.

Chan, J. K. L. \& Quah, W. B. (2008). Key issues on managing small and medium-sized accommodation business: an exploratory study. TEAM Journal of Hospitality \& Tourism, 5(1), 13-26.

Chandy, R. K., \& Tellis, G. J. (2000). The incumbent's curse? Incumbency, size and radical product innovation. Journal of Marketing, 64(3) 1-17.

Chaston, I., Badger, B., Mangles, T. \& Sadler-Smith, E. (2001). Organisational learning style, competencies and learning systems in small UK manufacturing firms. International Journal of Operations \& Production Management, 21(11), 1417-1432.

Corbett, C. \& Wassenhove, L. V. (1991). Trade-offs? What Trade-offs? Short Essay on Manufacturing Strategy. France, INSEAD. 1-20

Dawes, J. (1999). The relationship between subjective and objective company performance measures in market orientation research: further empirical evidence. Marketing Bulletin, 10(3) 65-75.

Ettlie, J. E. (1983). Organizational policy and innovation among suppliers to the food processing sector. Academy of Management Journal, 26, 27- 44.

Feng, M., Terziovski, M. \& Samson, D. (2007). Relationship of ISO 9001:2000 quality system certification with operational and business performance: a survey in Australia and New Zealandbased manufacturing and service companies. Journal of Manufacturing Technology Management, 19(1), 22-37.

Garces, S.A., Gorgemans, S., Sanchez, A.M., and Perez, M.P. (2004). Implications of the internet: an analysis of the aragonese hospitality industry, 2002. Tourism Management, 25(5), 603-613.
Gratzer, M. M. (2003). Changes in the travel and tourism industry caused by the internet - competitive advantage for the SME accommodation sector in Austria? Universität Wien, German.

Halim, D. M. A. S. A., Zakaria, D. Z., Hasnan, M. T. \& Muda, S. (2012). The direction of Terengganu tourism industry in sustaining business growth: a conceptual framework. International Journal of Academic Research in Business and Social Sciences, 2(4), 250-263.

Hong, W. and Zhu, K. (2006). Migrating to internetbased e-commerce: factors affecting e-commerce adoption and migration at the firm level. Information \& Management, 43(2), 204-221.

Kayadibi, S., Polat, R. \& Fidan, Y. (2013). Small and medium-sized business in Malaysia economy: case of Turkish entreprenuers in Kuala Lumpur.

Kotler, P. \& Keller, K. (2011). Marketing Management 14th Edition, Upper Saddle River, Nj, Prentice Hall.

Kim, S. W. (2006). Effects of supply chain management practices, integration and competition capability on performance. Supply Chain Management: An International Journal, 11(3), 241-248.

Law, R. \& Jogaratnam, G. (2005). A study of hotel information technology applications. International Journal of Contemporary Hospitality Management, 17(2), 170-180.

Morrison, A. \& Teixeira, R. (2004). Small business performance: a tourism sector focus. Journal of Small Business and Enterprise Development, 11(2), 166-173.

Morrison, A. \& Conway, F. (2007). The status of the small hotel firm. The Service Industries Journal, 27 (1), 47-58.

MOTAC, Ministry of Tourism, Art and Culture Malaysia. (2017). Rated Tourist Accommodation Premises. [Online] Available at: http://www.motac.gov.my [Accessed 11 September 2017].

Pallant, J. (2005). SPSS Survival Manual: A Step by Step Guide to Data Analysis Using SPSS. Maidenhead: Open University Press/McGraw-Hill,

Petridou, E., Sarri, A. \& Kyrgidou, L. P. (2009). Entrepreneurship education in higher educational institutions: the gender dimension. Gender in Management: An International Journal, 24(4), 286309.

Phan, D.D. (2003). E-business development for competitive advantages: a case study, Information \& Management. 40: 6 581-590 
Porter, M. E. (1985). Competitive advantage. New York, Free Press.

Porter, M. E. (1996). What is a strategy? Harvard Business Review. 74: 6 61-78

Raosoft (2004). Sample size calculator. [Online] Available at: www.raosoft.com/samplesize [Accessed 8 December 2017].

Roberts, P. W. \& Amit, R. (2003). The dynamics of innovative activity and competitive advantage: the case of Australian retail banking, 1981 to 1995. Organization Science, 14(2) 107-122.

Rosli, M. M. (2012). Competitive strategy of Malaysian small and medium enterprise: an exploratory investigation. American International Journal of Contemporary Research, 2(1), 93-105. 